\title{
SUPERIOR VENA CAVA TO PULMONARY ARTERY ANASTOMOSIS: AN ADJUNCT TO BIVENTRICULAR REPAIR
}

Glen S. Van Arsdell, MD ${ }^{\mathrm{a}}$ William G. Williams, $\mathrm{MD}^{\mathrm{a}}$ Catherine M. Maser, $\mathrm{RN}^{\mathrm{a}}$ Kim S. Streitenberger, RN ${ }^{\mathbf{a}}$ Ivan M. Rebeyka, MD

John G. Coles, $\mathrm{MD}^{\mathrm{a}}$

Robert M. Freedom, $\mathrm{MD}^{\mathrm{b}}$
From May 1981 to September 1995, 38 patients received a superior vena cava-pulmonary artery anastomosis in association with biventricular repair. Patients were divided into four groups on the basis of indication for operation. Group A (19 patients) had a small physiologic right ventricle defined by tricuspid anulus $\mathrm{z}$ values or predicted right ventricular volume. Group B (11 patients) had a functionally compromised right ventricle. Group C (four patients) consisted of those receiving a superior vena cava-pulmonary artery anastomosis as a facilitation to biventricular repair. Group D (four patients) was defined by acute postoperative right ventricular dysfunction. Age ranged from 5 months to 51 years (median 3.5 years). There were 14 different underlying primary diagnoses in this cohort and multiple associated anomalies. Operative mortality was as follows: group A, two of $19(10.5 \%)$; group B, two of $11(18 \%)$; group C, none of four $(0 \%)$; and group D, three of four (75\%). Follow-up is complete in 37 of 38 patients (97\%), ranging from 1 to 174 months (mean $46.3 \pm 36.9$ ). Twenty-two patients are in New York Heart Association functional class I and eight patients are in class II. No clinical evidence of cyanosis or protein-losing enteropathy has been detected. With the use of this adjunctive approach, acceptable intermediate-term outcomes were obtained in patients having an anatomically or functionally compromised pulmonary ventricle. The anastomosis safely facilitates repair in a subset of patients. Results for this procedure when used as a salvage operation for right ventricular dysfunction have not been satisfactory. (J Thorac Cardiovasc Surg 1996;112:1143-9)
In patients having morphologic defects of the ventricles, the heart is not always easily classified functionally as being univentricular or biventricular.

From the Divisions of Cardiovascular Surgery ${ }^{\mathrm{a}}$ and Cardiology, ${ }^{\mathrm{b}}$ Hospital for Sick Children Toronto, and The Toronto Congenital Cardiac Center for Adults, Toronto, Ontario, Canada.

Read at the Seventy-sixth Annual Meeting of The American Association for Thoracic Surgery, San Diego, Calif., April 28-May 1, 1996.

Received for publication May 6, 1996; revisions requested June 11, 1996; revisions received July 8, 1996; accepted for publication July 10, 1996.

Address for reprints: William G. Williams, MD, Hospital for Sick Children, Division of Cardiovascular Surgery, 555 University Ave., Toronto, Ontario M5G 2A1, Canada.

Copyright (C) 1996 by Mosby-Year Book, Inc.

$0022-5223 / 96 \$ 5.00+0 \quad \mathbf{1 2} / \mathbf{6} / \mathbf{7 6 3 3 7}$
Those patients believed to have predominantly a single ventricle have been treated surgically with Fontan's operation. ${ }^{1,2}$ Patients believed to have biventricular potential, even if the heart is not morphologically complete, may be treated by an attempt at biventricular repair. ${ }^{1-4}$ Fontan's operation for all patients with borderline pulmonary ventricles may not be ideal because of late outcome. ${ }^{5,6}$ Additionally, some physiologic benefit may be achieved from incorporating the pulmonary ventricle even if it is partially compromised. ${ }^{4,7,8}$

There is a subset of patients in whom the morphologic or functional status of the right ventricle falls between what clearly would accommodate a biventricular repair and what would require the Fontan procedure. These patients may benefit from volume unloading of the right ventricle as an asso- 
Table I. Indications for operation

\begin{tabular}{lr}
\hline Group A: Small pulmonary ventricle & 19 \\
Group B: Chronic right ventricular dysfunction & 11 \\
Group C: Facilitation of repair without size or functional & 4 \\
problems in the pulmonary ventricle & \\
Group D: Acute right ventricular dysfunction & 4 \\
\hline
\end{tabular}

Table II. Underlying primary diagnosis: Number of patients and group

\begin{tabular}{lccccc}
\hline & Total & $A$ & $B$ & $C$ & $D$ \\
\hline Ebstein's anomaly & 9 & & 9 & & \\
D-Transposition of the great arteries & 4 & 4 & & & \\
Atrioventricular and ventriculoarterial & 4 & 3 & & 1 & \\
$\quad$ discordance & & & & & \\
Pulmonary stenosis & 3 & 3 & & & \\
Tetralogy of Fallot & 3 & 2 & & & 1 \\
$\quad$ Ventricular septal defect(s) & 3 & 1 & & 1 & 1 \\
Pulmonary atresia with intact & 3 & 1 & 2 & & \\
$\quad$ ventricular septum & & & & & \\
Atrioventricular septal defect with left & 2 & & & 2 & \\
$\quad$ SVC and unroofed coronary sinus & & & & & \\
Atrial septal defect & 2 & 2 & & & \\
Double-inlet left ventricle with & 1 & & & & 1 \\
$\quad \begin{array}{l}\text { D-transposition of the great } \\
\text { arteries and pulmonary stenosis }\end{array}$ & & & & & \\
Double-outlet right ventricle & 1 & & & & 1 \\
Double-outlet right ventricle with & 1 & 1 & & & \\
$\quad$ atrioventricular discordance & & & & \\
$\quad$ Left atrial isomerism complex & 1 & 1 & & \\
Atrioventricular septal defect with & 1 & 1 & & \\
$\quad$ tetralogy of Fallot & & & &
\end{tabular}

ciated procedure to a biventricular repair. Among the ways this can be achieved is by directly anastomosing the superior vena cava (SVC) to the pulmonary artery (PA) or by atrial fenestration. ${ }^{1}$

Following is a report of SVC-PA anastomosis in the setting of biventricular repair of intracardiac defects. In these patients the pulmonary ventricles were judged to be compromised according to an assessment of volume or function. There is a small subset in whom the right ventricle was adequate but biventricular repair was facilitated by the SVC-PA anastomosis.

\section{Patients and methods}

The Division of Cardiovascular Surgery database search at the Hospital for Sick Children and the Toronto Congenital Cardiac Center for Adults defined 41 patients receiving an SVC-PA anastomosis in association with biventricular repair. The search collection period was between May 1981 and September 1995. Clinic and hospital records were analyzed. Follow-up was obtained by reviewing clinic records, contacting the patient's physician, and making telephone calls to the patient or family of the patient.

Patients having an SVC-PA anastomosis as palliation
Table III. Associated diagnosis

\begin{tabular}{lc}
\hline & No. of patients \\
\hline Ventricular septal defect & 8 \\
Pulmonary stenosis & 6 \\
Patent ductus arteriosus & 3 \\
Unroofed coronary sinus & 3 \\
Atrial septal defect & 2 \\
Coarctation of the aorta & 2 \\
Multiple ventricular septal defects & 2 \\
Down syndrome & 2 \\
Partial anomalous pulmonary return & 2 \\
Pulmonary atresia & 2 \\
Right aortic arch & 2 \\
Other & 10
\end{tabular}

alone or as a staging procedure to the Fontan operation were excluded. Three patients who had biventricular repair, as well as an SVC-PA anastomosis, were excluded, two because the SVC-PA anastomosis was therapy for cannulation site stenosis of the SVC, and one because the SVC-PA anastomosis was therapy for cyanosis induced by the PA band. The first two children did well. The third child had biventricular repair despite having a small systemic ventricle and subsequently died of complications related to that ventricle. The SVC-PA anastomosis was not taken down at the time of biventricular repair. The indication for SVC-PA anastomosis in these three excluded patients was not pulmonary ventricular size or function, nor was it to facilitate the biventricular repair.

An SVC-PA anastomosis was performed in the remaining 38 patients because the pulmonary ventricle was compromised as judged by morphologic features or function. In a small subset the SVC-PA anastomosis was done as an integral component of the operation at the time of biventricular repair. Ages ranged from 5 months to 51 years (median 3.5 years). There were 21 male and 17 female patients. These patients were classified into four groups (see Table I) on the basis of the indications for operation. The hemodynamic guidelines for cavopulmonary anastomosis have been previously outlined. ${ }^{9}$

Group A consisted of 19 patients having a small physiologic right ventricle defined by tricuspid $\mathrm{z}$ values or predicted ventricular volume. The tricuspid anulus was measured by echocardiography, by cardiac catheterization, or by intraoperative assessment and then plotted on a nomogram ${ }^{10}$ with the given body surface area to elicit the $z$ value. Predicted right ventricular volume was obtained with the use of the Simpson biplane algorithm. ${ }^{11}$ Fourteen patients had a tricuspid mean $\mathrm{z}$ value of -3.7 (standard deviation \pm 1.4 ). Five patients had a mean predicted right ventricular volume of $77.8 \%$ (standard deviation $\pm 8 \%$ ). Table II lists the underlying diagnosis for all groups. Associated diagnoses for all groups are in Table III.

Group B included 11 patients, those having a functionally compromised pulmonary ventricle as a result of Ebstein's anomaly (nine patients) or pulmonary atresia with intact ventricular septum (two patients). Eight patients with Ebstein's anomaly had moderate or severe reduction in right ventricular contractility, three had 
Table IV. Associated operations before $S V C-P A$ anastomosis

$\begin{array}{ll}\text { Atrial septostomy } & 9 \\ \text { Systemic-PA shunt } & 9 \\ \text { PA band } & 4 \\ \text { Pulmonary valvotomy } & 4 \\ \text { Right ventricular outflow patch } & 4 \\ \text { Arterial switch } & 2 \\ \text { Systemic-PA shunt closure } & 2 \\ \text { Ventricular septal defect repair } & 2 \\ \text { Other } & 4\end{array}$

partially obstructing lesions to the right ventricular outflow tract, and two had right ventricular cavities less than $75 \%$ of normal. Four patients had more than one of the previously mentioned criteria. The two remaining group $\mathrm{B}$ patients had one each of the following: hemodynamic failure with catheter balloon occlusion of an atrial septal defect or a dilated (146\% of predicted) right ventricle with poor contractility.

Group C consisted of four patients in whom there were no functional or size defects in the pulmonary ventricle; however, the biventricular repair was facilitated by performing an SVC-PA anastomosis. Three of these patients had a left SVC. That component of the right-to-left shunt was eliminated by performing a left bidirectional cavopulmonary anastomosis. The patient with atrioventricular and ventriculoarterial discordance had a double switch operation. ${ }^{12}$ A right bidirectional cavopulmonary shunt eliminated the potential obstruction to SVC drainage.

Group D consisted of four patients having acute hemodynamic or functional right ventricular failure. Salvage was attempted by performing an SVC-PA anastomosis. Two of these anastomoses were performed because of high right ventricular pressures after repair (double-inlet left ventricle with septation procedure and multiple ventricular septal defects with postoperative study demonstrating a right ventricular cavity $62 \%$ of predicted) and two because of postoperative right ventricular failure. The latter two had patching of the right ventricular outflow tract and one had an insertion of a pulmonary valve. The procedures were performed 2 and 3 days after the initial repair.

There were multiple associated anatomic defects necessitating repair in these patients. Twenty patients had a procedure before the SVC-PA anastomosis, and 11 of the 20 had multiple procedures or multiple components to the procedure (Table IV). Thirty-three of 38 patients had an associated procedure at the time of SVC-PA anastomosis. Of these, 24 had multiple components to the procedure (Table V). Seven patients had operations after the SVC-PA anastomosis, and four of these patients had multiple components to the associated procedure (Table VI).

Biventricular repair was considered complete when all septal defects were closed. The SVC-PA anastomosis was performed in conjunction with biventricular repair in 29 patients, as a stage to biventricular repair in six, and after biventricular repair in three patients.

Thirty patients received a bidirectional cavopulmonary anastomosis: 25 right SVC-PA anastomoses, four left
Table V. Associated procedures at the time of SVC-PA anastomosis

\begin{tabular}{lr} 
Atrial septal defect closure (nonprimum) & 15 \\
Closure of ventricular septal defect(s) & 6 \\
Pulmonary arterioplasty & 4 \\
Pulmonary valve replacement & 4 \\
Tricuspid valve repair & 4 \\
Systemic-PA shunt ligation & 4 \\
Double switch operation & 3 \\
Patent ductus arteriosus ligation & 3 \\
PA band removal & 3 \\
Tricuspid valve replacement & 3 \\
Atrioventricular septal defect repair & 2 \\
Conduit to PA & 2 \\
Mustard procedure & 2 \\
Pulmonary valvotomy & 2 \\
Right ventricular outflow patch & 2 \\
Subaortic stenosis resection & 2 \\
Ventricular septal defect enlargement & 2 \\
Other & 11 \\
\hline
\end{tabular}

Table VI. Associated operations after SVC-PA anastomosis

Atrial septal defect closure
Pulmonary arterioplasty
Pulmonary valve replacement
Pacemaker
Tricuspid valve replacement
Ventricular septal defect repair
Other

SVC-PA anastomoses, and one bilateral anastomosis. Six patients received a side-to-side cavopulmonary anastomosis and two a classic Glenn shunt.

\section{Results}

Operative mortality, defined as mortality associated with any cardiac operation, is as follows: group A, two of 19 patients $(10.5 \%)$; group $\mathrm{B}$, two of 11 patients $(18 \%)$; group $\mathrm{C}$, none of four patients $(0 \%)$; and group $\mathrm{D}$, three of four patients $(75 \%)$. Seven patients died of low output syndrome. One patient died as a consequence of air embolus. Before death one patient each had been treated with an aortic balloon pump and extracorporeal membrane oxygenation. One patient had a subdural hematoma. Autopsy demonstrated small pulmonary arteries in another patient.

Average stay in the intensive care unit was 7.1 days (standard deviation \pm 11.5 days). Three children had prolonged stays of 28,33 , and 63 days. Mean postoperative central venous pressure measured in the second 12 hours after the operation and 
available in 35 patients was $14.9 \mathrm{~mm} \mathrm{Hg}$ (standard deviation $\pm 4.9 \mathrm{~mm} \mathrm{Hg}$ ). Only two of the surviving patients had a central venous pressure of $20 \mathrm{~mm} \mathrm{Hg}$ or more, whereas four of the seven patients who died had a central venous pressure of $20 \mathrm{~mm} \mathrm{Hg}$ or more. Transcutaneous oxygen saturation data with the patient breathing room air is available on 21 patients after the operation or after discharge and averaged $94.8 \%$ (standard deviation $\pm 2.7 \%$ ) Eight patients had a postoperative pleural effusion, two had mediastinitis, two had chylous drainage, and one had postpericardiotomy syndrome.

Twelve patients had cardiac catheterization studies after SVC-PA anastomosis. Three of these studies were performed because of postoperative hemodynamic problems. One patient with atrioventricular septal defect and tetralogy of Fallot had a mean postoperative PA pressure of $26 \mathrm{~mm} \mathrm{Hg}$. This patient had takedown of the SVC-PA anastomosis and creation of an atrial septal defect 2 weeks after the initial repair. Forty months later the atrial septal defect was closed. A second child received an atrial blade septostomy 6 days after biventricular repair. Indications for the septostomy were low cardiac output syndrome associated with elevated right-sided filling pressures. This septostomy remains open nearly 3 years later. Another child had aneurysmal dilation of the left SVC-PA anastomosis. The aneurysm was 1.8 by $2.2 \mathrm{~cm}$ and necessitated resection and ligation 10 months after repair. ${ }^{13}$ Three children received catheter interventions consisting of one device closure of a patent ductus arteriosus and two PA dilations. Three patients had small residual muscular ventricular septal defects. One child with a classic Glenn shunt had an SVC-right atrium fistula that was later surgically closed. One child with a side-to-side SVC-PA anastomosis had contrast material going from the PA to the right atrium. No pulmonary arteriovenous fistulas were identified.

Follow-up data are complete on 37 of 38 patients (97\%), ranging from 1 month to 174 months (mean $46.3 \pm 36.9$ months). Two patients with atrioventricular and ventriculoarterial discordance (corrected transposition) have required pacemakers. Twentytwo patients are in New York Heart Association functional class I and eight are in class II. There was no evidence of protein-losing enteropathy or cyanosis.

\section{Discussion}

Compromise of the pulmonary ventricle can occur with both morphologic and functional problems. One way of defining a morphologic defect is the tricuspid $\mathrm{z}$ value, which indicates the valve size as compared with "normal" valve size ${ }^{10}$ In some patients this also reflects the corresponding ventricular volume. ${ }^{14}$ However, it is possible to have a normal tricuspid $\mathrm{z}$ value and yet an anatomically small right ventricle. The converse may occur as well. In these situations the Simpson biplane algorithm is helpful in estimating predicted volume on a percentage basis. ${ }^{11}$ Ventricles with small tricuspid $\mathrm{z}$ values or a small volume capacity have a diminished ability to handle systemic venous return. An acute or chronic decrease in contractility in the pulmonary ventricle also affects its ability to cope with a normal volume load.

Incorporating a compromised pulmonary ventricle into the circulation can be accomplished in several ways. A standard biventricular repair may be performed if the functional capacity is only mildly diminished. If the capacity is inadequate, a standard repair and atrial fenestration can be done, ${ }^{1,2}$ or a biventricular repair supplemented with an SVC-PA anastomosis can be performed to volume unload the right ventricle. ${ }^{1,3,4,8}$ In the latter case an atrial fenestration can also be added. Atrial fenestration may be effective; however, volume loading of the heart continues and the appropriate fenestration size may not be predictable, leaving the possibility of right heart failure or inappropriate systemic desaturation. There is also a risk of paradoxic emboli.

Advantages to performing an SVC-PA anastomosis with complete repair are that right ventricular volume loading is reduced without increasing the left ventricular volume load. Systemic saturation is complete, and there is no risk of paradoxic emboli.

This type of repair has been known as a biventricular repair with a pulsatile cavopulmonary anastomosis. ${ }^{4}$ It may also be thought of as a one and one-half ventricle repair.

There are potential complications in exposing the SVC to pulsatile flow and the pulmonary arteries to a cavopulmonary shunt. Two of the 38 patients $(5 \%)$ had complications related to altered hemodynamics in the SVC necessitating takedown of the SVC-PA anastomosis, one because of aneurysmal dilation and the other because of elevated SVC pressures. To date there has been no evidence of pulmonary arteriovenous fistula. Increased chylous drainage ${ }^{15}$ and pleural effusions ${ }^{16}$ have previously been reported. Bilateral PA flow from the bidirectional SVC-PA anastomosis has been demonstrated ${ }^{17,18}$ even with forward flow from the main PA. This may 
explain the lack of clinical evidence for pulmonary arteriovenous fistulas.

Several different types of cavopulmonary anastomosis were performed in this series. The current practice is to perform a bidirectional cavopulmonary anastomosis. A classic Glenn anastomosis has potential problems with discontinuity of the PAs and pulmonary arteriovenous fistula. ${ }^{19} \mathrm{~A}$ side-to-side SVC-PA anastomosis leaves the possibility of circular flow. A postoperative catheterization study showed circular flow in one patient in this series. Gentles and associates ${ }^{8}$ have prevented this problem by ligating the right PA medial to the anastomosis.

The technique of augmenting a biventricular repair with an SVC-PA anastomosis has been reported previously in less heterogeneous groups. Alvarado and associates ${ }^{3}$ have reported on nine patients having an atrioventricular septal defect and a small right ventricle who were treated by standard repair and a bidirectional cavopulmonary shunt. Echocardiographic assessment of early postoperative blood flow patterns demonstrated atrial augmentation of PA flow and systolic reversal of flow in the SVC. At 6 weeks, the atrial component of PA flow was no longer present, and the SVC flow demonstrated less dependence or no dependence on ventricular systole. Tricuspid $\mathrm{z}$ values in this series were as low as -10 . There was no mortality.

Billingsley and colleagues ${ }^{1}$ also reported the use of SVC-PA anastomosis in patients having pulmonary atresia with intact ventricular septum. These patients had a moderately diminished right ventricular size. A postoperative cardiac catheterization demonstrated an atrial contribution to pulmonary flow.

de Leval and associates ${ }^{2}$ reported an $80 \%$ mortality with complete repair of pulmonary atresia with intact ventricular septum when the tricuspid anulus was less than three standard deviations (99\% confidence limits) below normal. Conversely, those having a tricuspid anulus larger than that level had an $84 \%$ survival at the time of complete repair. We believe operative mortality may be improved by performing an SVC-PA anastomosis in those patients having a tricuspid anulus less than 3 standard deviations below normal.

Patients with morphologic intracardiac defects in whom the indexed size and functional status of the physiologic right ventricle are marginal or inadequate may be treated by a Fontan procedure. ${ }^{1,2}$ However, Ilbawi and coworkers ${ }^{7}$ have reported experimental evidence suggesting that favorable he- modynamic effects from the right ventricle to the PA remain even when the right ventricle is reduced to nearly $30 \%$ of normal. The subset of patients with a compromised pulmonary ventricle may benefit from incorporating even a poorly functioning right ventricle into the repair.

In this series, performing an SVC-PA anastomosis as a salvage operation for acute right ventricular failure was disappointing. This report does demonstrate the ability to perform a biventricular repair in the face of a chronically compromised pulmonary ventricle. The limits, in terms of decreased size or function of the pulmonary ventricle, and biventricular repair augmented with an SVC-PA anastomosis are not clear. Successful treatment using the adjunctive approach was achieved in patients with tricuspid anulus $z$ values as small as -6 or predicted right ventricular volumes as small as $47 \%$; however, the child with a predicted right ventricular volume of $47 \%$ required a postoperative atrial blade septostomy.

More difficult to quantify is the functional capacity of a ventricle when size is not an issue. Some of the decisions for creation of an SVC-PA anastomosis are made on an impression that the right ventricle is inadequate. In this series, a moderately dilated right ventricle with moderately reduced ventricular function was an indication for the adjunctive approach, as was a dilated right ventricle with volume unloading occurring through an atrial septal defect. Patients with adequate ventricular function and a potentially obstructive anterior tricuspid leaflet in Ebstein's anomaly may benefit as well.

There are anatomic subtypes whose operation is simplified by such an approach. An example is the combination of left SVC, unroofed coronary sinus, and atrioventricular septal defect. Patients with physiologically corrected transposition undergoing an atrial baffle inversion and morphologic right ventricle-PA conduit (double switch procedure) can benefit in three ways: a potential obstructing point in the SVC portion of the atrial baffle is eliminated, more intraatrial room is available for pulmonary venous return, and an already borderline sized right ventricle made smaller by the conduit is volume unloaded.

\section{REFERENCES}

1. Billingsley AM, Laks H, Boyce SW, George B, Santulli T, Williams RG. Definitive repair in patients with pulmonary atresia and intact ventricular septum. J Thorac Cardiovasc Surg 1989;97:746-54.

2. de Leval M, Bull C, Hopkins R, et al. Decision making in the 
definitive repair of the heart with a small right ventricle. Circulation 1985;72(Suppl):II52-60.

3. Alvarado O, Sreeram N, McKay R, Boyd IM. Cavopulmonary connection in repair of atrioventricular septal defect with small right ventricle. Ann Thorac Surg 1993;55:729-36.

4. Muster AJ, Zales VR, Ilbawi MN, Backer CL, Duffy CE, Mavroudis C. Biventricular repair of hypoplastic right ventricle assisted by pulsatile bidirectional cavopulmonary anastomosis. J Thorac Cardiovasc Surg 1993;105:112-9.

5. Fontan F, Kirklin JW, Fernandez G, et al. Outcome after a "perfect" Fontan operation. Circulation 1990;81:1520-36.

6. Driscoll DJ, Offord KP, Feldt RH, Schaff HV, Puga FJ, Danielson GK. Five to fifteen year follow-up after Fontan operation. Circulation 1992;85:469-96.

7. Ilbawi MN, Idriss FS, DeLeon SY, et al. When should the hypoplastic right ventricle be used in a Fontan operation? An experimental and clinical correlation. Ann Thorac Surg 1989; 47:533-8.

8. Gentles TL, Keane JF, Jonas RA, Marx GE, Mayer JE. Surgical alternatives to the Fontan procedure incorporating a hypoplastic right ventricle. Circulation 1994; 90(Suppl):II1-6.

9. Alejos JC, Williams RG, Jarmakani JM, et al. Factors influencing survival in patients undergoing the bidirectional Glenn anastomosis. Am J Cardiol 1995;75:1048-50.

10. Kirklin JW, Barratt-Boyes BG. Anatomy, dimensions and terminology. Cardiac surgery. 2nd ed. New York: Churchill Livingstone, 1993:32.

11. Graham TP, Jarmakani JM, Atwood GF, Canent R. Right ventricular volume determinations in children: normal values and observations with volume or pressure overload. Circulation 1973;47:144-53.

12. Ilbawi $\mathrm{MN}$, DeLeon SY, Backer CL, et al. An alternative approach to the surgical management of physiologically corrected transposition with ventricular septal defect and pulmonary stenosis or atresia. J Thorac Cardiovasc Surg 1990;100:410-5.

13. Teske DW, Davis T, Allen HD. Cavopuimonary anastomotic aneurysm: a complication in pulsatile pulmonary arteries. Ann Thorac Surg 1994;57:1661-4.

14. Hanley FL, Sade RM, Blackstone EH, Kirklin JW, Freedom RM, Nanda NC. Outcomes in neonatal pulmonary atresia with intact ventricular septum: a multi-institutional study. J Thorac Cardiovasc Surg 1993;105:406-27.

15. Frommelt MA, Frommelt PC, Berger S, et al. Does an additional source of pulmonary blood flow alter outcome after a bidirectional cavopulmonary shunt? Circulation 1995; 92(Suppl):II240-4.

16. Mainwaring RD, Lamberti JJ, Uzark K, Spicer RL. Bidirectional Glenn. Is accessory pulmonary blood flow good or bad? Circulation 1995;92(Suppl):II294-7.

17. Lamberti JJ, Spicer RL, Waldman JD, et al. The bidirectional cavopulmonary shunt. J Thorac Cardiovasc Surg 1990;100: 22-30.

18. Kobayashi J, Matsuda H, Nakano S, et al. Hemodynamic effects of bidirectional cavopulmonary shunt with pulsatile pulmonary flow. Circulation 1991;84(Suppl):III219-25.

19. McFaul RC, Tajik AJ, Mair DD, Danielson GK, Seward JB. Development of pulmonary arteriovenous shunt after superior vena cava-right pulmonary artery (Glenn) anastomosis. Circulation 1977;55:212-6.

\section{Discussion}

Dr. Frank L. Hanley (San Francisco, Calif.). This presentation brings into focus a concept that has been evolving over the past several decades in congenital heart disease, and that is that there is an emphasis on tailoring the operation to the unique physiology of each patient with complex congenital heart disease rather than subjecting a group of patients with variable physiology to a single predetermined operation. This can only continue to increase and improve outcome.

I have several comments and questions regarding your individual patient groups. In groups A and B, the patients with either small right ventricles or chronically dysfunctional right ventricles, have you evaluated the exercise tolerance of normal subjects and that of patients with completed Fontan operations to see how they compare in terms of performance?

Another point, in your group $\mathrm{C}$ patients, three had the left SVC with unroofed coronary sinus as part of their lesion. Reading between the lines, I would assume that you and your group believe that the more standard intraatrial baffle type of repair is somewhat cumbersome. I personally would agree with that. The way we have approached this is a little bit different, and I would like your comments on it. We have transected the left SVC and brought it over to the right SVC or to the tip of the right atrial appendage. We have done this in three infants with complex atrioventricular canal defects, and they have all been young infants or neonates. Either approach is acceptable, but age may be an important factor in choosing the most desirable technique in neonates and small infants. The cavopulmonary anastomosis is not an option in the neonate. How early do you feel comfortable doing the cavopulmonary anastomosis in this setting?

Regarding one of your other patients in group $\mathrm{C}$, the patient with the double switch, we agree that it is possible to get excellent results doing a so-called bidirectional cavopulmonary shunt. In our series of double switches, we now consider it the procedure of choice, or a component of the procedure of choice. You brought up the advantage in your manuscript of avoiding SVC obstruction during the double switch. There also are a number of other advantages: It decreases suture load in the right atrium; it stays away from the sinoatrial node, so that the all important rhythm issues are likely to be better with intraatrial repairs; and it also decreases the crossclamp time because a cavopulmonary shunt can be done after the crossclamp has been removed.

Finally, there may be a group E, if you will, those patients who have already undergone a bidirectional Glenn as a staged procedure in the Fontan tract. These are patients with complex anatomy who have two good ventricles, however. We have opted to do biventricular repairs in such patients, rather than continue with the Fontan procedure. We have opted to leave the Glenn in place and not take it down to make the anatomy and the physiology completely normal. I would like your opinion on this, whether you have been faced with this situation and whether you agree or disagree with leaving the cavopulmonary connection intact at the time of repair.

Dr. Van Arsdell. Thank you, Dr. Hanley. Regarding exercise tolerance in groups $\mathrm{A}$ and $\mathrm{B}$, unfortunately only 
one patient has had a maximal oxygen uptake study. That was $21 \mathrm{ml} / \mathrm{kg}$ per minute, which is comparable with results in some patients who have had the Fontan operation. That patient had Ebstein's anomaly. We have not extensively studied this but hope to in the future.

The concept of moving the left SVC to the right side is a good one. There are a number of things that are troublesome about performing a cavopulmonary anastomosis when there is still forward flow through the PA. Mainwaring and Frommelt each have looked at cavopulmonary anastomosis when there has been an alternate source of systemic flow to the PA. They found an increase in chylothorax and pleural effusions. Our experience corroborates that data. There also is some concern as to what kind of SVC problems will develop in the long run when there is normal flow through the PA. One patient in this series had a left SVC aneurysm, and although this complication is uncommon, it is something that we have to consider. This is not a benign procedure; however, it probably is appropriate in a number of circumstances.

I agree with your thoughts on the double switch. The concept of having a better rhythm is certainly very important. We find the operation easier to perform by doing a cavopulmonary anastomosis. It is troublesome to do the superior limb of a Mustard-type procedure. Additionally, there is increased room in the atrium for the pulmonary venous return to get to the systemic ventricle. Many of these patients have a borderline pulmonary ventricle. By the time you perform an intracardiac tunnel and ventriculotomy for the conduit, you significantly further compromise that ventricle. It therefore may be very advantageous in the double switch operation.

Your group $\mathrm{E}$ is a good thought, and in terms of the physiology, it goes along well with the group $\mathrm{C}$ patients. These are patients with a previous cavopulmonary anastomosis but who in reality have morphologic characteristics amenable to biventricular repair. We would most likely evaluate these patients according to the criteria of this paper and tailor the operation to the individual patient.

We have performed cavopulmonary anastomosis in infants as young as 2 to 3 months of age in the setting of hypoplastic left heart. Because the PA pressures are elevated in atrioventricular septal defect, one wonders if that experience is transferable.

Dr. Francis Robicsek (Charlotte, N.C.). I enjoyed this very interesting paper. However, I would like to sound some reservation regarding the evaluation presented on adding superior cavopulmonary anastomosis to the complex conditions described. In the late 1950 s and early 1960 s we operated on a sizable group of patients, who were comparable both in numbers and in diagnosis to those described by Dr. Van Arsdell, doing only cavopulmonary shunts. The mortality rate was less and the immediate postoperative results were comparable with those described by the authors. Thus it is possible that the clinical improvement observed by the authors was due to cavopulmonary anastomosis alone, and in some cases the biventricular repair had been irrelevant as far as the results are concerned. Our first patient in whom we performed a "preclassic" cavopulmonary anastomosis in 1957 for hypoplastic right ventricle is still alive, doing well, and fully employed. I would also like to add that both Kirklin and Björk a long time ago pointed out the compatibility of cavopulmonary anastomosis with complex intracardiac repairs.

Dr. Van Arsdell. Thank you, Dr. Robicsek. There are a couple of things that are different about the experience of the 1950 s and 1960 s from now. In that time, generally a classic Glenn was performed, and a number of those patients did have a satisfactory long-term outcome. A number of them also had late problems that have been well described in the literature. We have tried to avoid that by currently primarily doing a bidirectional cavopulmonary shunt.

Dr. Ilbawi has performed animal experiments in which he "downsized" the right ventricle to as small as $30 \%$ and hemodynamics in the PA remained favorable. Without having any concrete data, my inclination would be to say that a portion of this favorable outcome is due to the cavopulmonary shunt, but certainly a portion of it is attributable to a functioning right ventricle.

Dr. Adnan Cobanoglu (Portland, Ore.). Do you have any experience in patients who come to cardiac transplantation after a Fontan operation in which a bidirectional Glenn anastomosis may already have been performed? That may be a scenario in which you would take the load off the right ventricle in the most critical period, the first few days after transplantation. Do you have any experience with that? Would this be a good group in which to leave the Glenn connection alone and just do a single inferior vena cava connection to the new heart as far as systemic venous return to the right side is concerned?

Dr. Van Arsdell. I do not have any experience with that exact scenario, but our general philosophy is to perform a complete correction with transplantation. I would be concerned about leaving a cavopulmonary anastomosis in somebody who is undergoing transplantation, given that many of those patients had elevated pulmonary vascular resistance for a period of time. This could be troublesome. We would be inclined to take it down and do a cavocaval anastomosis.

Dr. Fred A. Crawford (Charleston, S.C.). Do you plan to continue to use this as a salvage procedure, and, if so, what exactly are your indications?

Dr. Van Arsdell. Patients who had this as a salvage operation when they had severe right ventricular failure in the intensive care unit after some type of biventricular repair did not survive. It may be successful in patients who have had a biventricular repair and, when they come off bypass, have a very elevated central venous pressure, low PA pressures, and no evidence of obstruction in the right ventricular outflow tract. The one patient in group $D$ that survived had this type of situation. 